\title{
High frequency pulse anodising of recycled 5006 aluminium alloy for optimised decorative appearance
}

\author{
Jensen, Flemming; Kongstad, Ib; Dirscherl, Kai; Gudla, Visweswara Chakravarthy; Ambat, Rajan
}

Published in:

Surface and Coatings Technology

Link to article, DOI:

10.1016/j.surfcoat.2019.04.024

Publication date:

2019

Document Version

Peer reviewed version

Link back to DTU Orbit

Citation (APA):

Jensen, F., Kongstad, I., Dirscherl, K., Gudla, V. C., \& Ambat, R. (2019). High frequency pulse anodising of recycled 5006 aluminium alloy for optimised decorative appearance. Surface and Coatings Technology, 368, $42-$ 50. https://doi.org/10.1016/j.surfcoat.2019.04.024

\section{General rights}

Copyright and moral rights for the publications made accessible in the public portal are retained by the authors and/or other copyright owners and it is a condition of accessing publications that users recognise and abide by the legal requirements associated with these rights.

- Users may download and print one copy of any publication from the public portal for the purpose of private study or research.

- You may not further distribute the material or use it for any profit-making activity or commercial gain

- You may freely distribute the URL identifying the publication in the public portal 


\section{Accepted Manuscript}

High frequency pulse anodising of recycled 5006 aluminium alloy for optimised decorative appearance

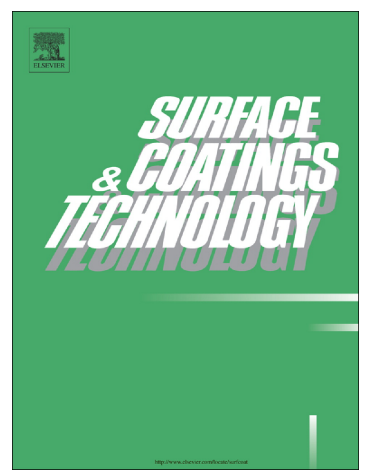

Flemming Jensen, Ib Kongstad, Kai Dirscherl, Visweswara Chakravarthy Gudla, Rajan Ambat

PII: $\quad$ S0257-8972(19)30389-5

DOI: $\quad$ https://doi.org/10.1016/j.surfcoat.2019.04.024

Reference: $\quad$ SCT 24519

To appear in: $\quad$ Surface \& Coatings Technology

Received date: $\quad$ 24 January 2019

Revised date: $\quad 5$ April 2019

Accepted date: $\quad 6$ April 2019

Please cite this article as: F. Jensen, I. Kongstad, K. Dirscherl, et al., High frequency pulse anodising of recycled 5006 aluminium alloy for optimised decorative appearance, Surface \& Coatings Technology, https://doi.org/10.1016/j.surfcoat.2019.04.024

This is a PDF file of an unedited manuscript that has been accepted for publication. As a service to our customers we are providing this early version of the manuscript. The manuscript will undergo copyediting, typesetting, and review of the resulting proof before it is published in its final form. Please note that during the production process errors may be discovered which could affect the content, and all legal disclaimers that apply to the journal pertain. 


\title{
High Frequency Pulse Anodising of Recycled 5006 Aluminium Alloy for Optimised Decorative Appearance
}

Jensen, Flemming ${ }^{1,2}$, Kongstad, $\mathrm{Ib}^{2}$, Dirscherl, Kai ${ }^{3}$, Gudla, Visweswara Chakravarthy ${ }^{1,4}$ Ambat, Rajan ${ }^{1}$.

${ }^{\mathbf{1}}$ Technical University of Denmark, Department of Mechanical Engineering, Section of Materials and Surface Engineering, Produktionstorvet, 2800 Kgs. Lyngby, Denmark

${ }^{2}$ Bang \& Olufsen A/S, Peter Bangs Vej 15, 7600 Struer, Denmark

${ }^{3}$ Denmark’s National Metrology Institute DFM, Kogle Allé 5, 2970 Hørsholm, Denmark

${ }^{4}$ The University of Manchester, School of Materials, Henry Moseley X-Ray Imaging Facility, Alan Turing Building, Upper Brook Street, M13 9PL Manchester, United Kingdom

\begin{abstract}
High frequency (HF) pulse anodising of a recycled AA5006 Aluminium alloy has been investigated to understand the effect of pulse anodising on improvements in optical quality of anodised surfaces in a sulphuric acid bath. The investigation includes the effect of applied voltage petential and pulse frequency on the anodising kinetics and optical properties of the recycled alloy with high number of intermetallic phases. The effect is compared with anodised surfaces produced using conventional DC anodising. Both the anodising kinetics and optical properties are largely dependent on the applied pulse frequency and amplitude of the anodising voltage. Surface gloss of the layer is generally improved upon using pulses compared to DC and improved by lowering the anodising voltage-potential and increasing the pulse frequency. Improved kinetics under pulse mode allows for getting good anodic layers even with voltage levels lower than $10 \mathrm{~V}$, however the surface gloss worsens when anodising below $10 \mathrm{~V}$. The benefit from pulse anodising is found to be largely due to metal-oxide interface roughness rather than on the structure and composition of the anodised layer.
\end{abstract}


Keywords: Recycled Aluminium; AA5006; Pulse Anodising; High Frequency; Optical Appearance; Kinetics 
1 Introduction

Aluminium alloys are often subjected to an anodising treatment to provide a thick alumina layer that offers pleasing decorative, higher corrosion resistance, enhanced scratch and wear resistance, thereby improving the value of the product [1-3]. A highly decorative anodic film, which often is obtained by Direct Current (DC) anodising in sulphuric acid, is greatly influenced by the anodising parameters as well as the alloy composition, microstructure, and surface morphology [4-7] The appearance of the anodised surface can vary greatly especially when using different alloys, despite the utilisation of similar process parameters [1,8]. The microstructure of the aluminium alloy plays has a crucial role due to differences in the electrochemical nature of second phase particles that react differently during the course of anodising. These differences usually originate from the intermetallic phase morphology, size, distribution, and composition. As such, any difference in the oxidation or/and dissolution of the microstructural constituents results in unintentional roughening of the metal/oxide interface as well as local variations in the anodic pore structure that eventually compromises the decorative appearance of the anodised surface. This especially becomes crucial for secondary/recycled aluminium alloys due to the higher amount of secondary phases, as compared to primary aluminium leading to undesirable effects on the anodic film [9]. The effect usually manifest in the form of light or dark streaks on the anodised surface, and darkening of the anodic films [8]. Akeret et al. [10] studied the effect of different intermetallic particles on the optical appearance of anodised surfaces and concluded that small electrochemically anodic intermetallics such as $\mathrm{Mg}_{2} \mathrm{Si}$ and $\mathrm{Mg}_{2} \mathrm{Al}_{3}$ have only a marginal effect on the anodised appearance, whereas electrochemically cathodic intermetallics especially iron and silicon rich, have large effect on the anodised appearance. A study by Van Gils et al. [11] found that rolled aluminium has approximately $10 \%$ lower reflectance compared to magnetron sputtered aluminium. It was 
concluded that the major reason for this reduced reflectance is presence of deformed layers $(1.2 \mu \mathrm{m}$ and $2.9 \mu \mathrm{m}$ in thickness) near the surface, which are created during the rolling process. Tabrizian et al. [4] found that a high gloss heat treated AA6060 material shows lower reflectance after anodising compared to a non-heat treated material. . The influencing factors were postulated to be inhomogeneity and imperfections in the anodised layer, and that the oxide-substrate interface roughness has little influence on the visual appearance. Saito et al. [12] measured the optical transmission properties of $50 \mu \mathrm{m}$ anodic films that were formed from pure aluminium and compared to alloy AA5052. The pure aluminium oxide proved transparent with a transmittance of 80-90\%, whereas the AA5052 oxide had a dark colour with a transmittance of just $20-30 \%$. The dark colour was found to be caused by many holes within the anodic film and an irregular cell structure.

In addition to being optically defect-free for best appearance, most of the industrial applications for anodic oxide films also call for good mechanical properties, hardness, corrosion and abrasion resistance. In order to meet these requirements, often thick and dense oxide films are formed on the aluminium substrates. Low electrolyte temperatures and higher anodic current densities enable the formation of hard and dense films, but due to effects, such as anodic film burning, the formation of defect free mechanically and optically sound thick anodic films can be challenging [13]. Burning of anodic films is often avoided by adopting a relatively high electrolyte temperature and low current density, but these parameters then increase the risk of anodic oxide powdering, and thick films are almost impossible to form [14]. To overcome these issues, low frequency pulse anodising has been studied for different conditions and for alloys with heterogeneous microstructures [15-21]. Low frequency pulse anodising is based on the recovery effect as argued by Yokoyama et al. [17] who also found that pulses improve oxide uniformity and reduce the total time required to produce a given film thickness. Ono et al. [22] increased the pulse 
frequency into the kilohertz regime to determine the beneficial effect on cast AlSi alloys (AC8A). It was concluded that the film thickness uniformity was improved by applying high-frequency switching electrolysis technique with positive and negative voltage cycles. Recently, Gudla et $\mathrm{al}[23,24]$ investigated the effect of high frequency pulse anodising of friction stir processed $\mathrm{Al}-\mathrm{TiO}_{2}$ composites, finding the effect of anodising parameters on the structure and morphology of the anodic layers. The so-called pulse-reverse-pulse anodising technique using a negative voltage potential in the low voltage cycle, provided extensive pore branching and pore generation at the particle-alumina matrix interface. However, the pulse anodising technique using zero voltage potential during the off-cycle showed no such features in the pore morphology, but only entrapment of $\mathrm{TiO}_{2}$ particles into the anodic alumina similar to that observed for DC anodising $[23,25]$. In a separate study [26], the effect of high frequency pulse anodising on heat treated magnetron sputtered $\mathrm{Al}-\mathrm{Zr}$ and $\mathrm{Al}-\mathrm{Ti}$ coatings was also investigated. It was concluded that pulse anodising offers an increased growth rate compared to conventional DC anodising, while also offering an improvement of surface reflectance. These observations were confirmed by Jensen et. al [27] . Furthermore, the anodised layer was more homogeneous in terms of the degree of oxidation of the intermetallic phases for high frequency pulse anodising when compared to those observed for conventional DC anodising of similar material systems [28-30].

As previously mentioned, studies have shown the importance of the alloy composition, morphology and microstructure of the Al surface and its effect on the anodising behaviour and optical appearance $[31,32]$. From an industrial perspective, it is very attractive to have a process that can improve the decorative appearance of a low-cost recycled material, as an alternative to the existing method of using high-cost primary aluminium. In view of the growing interest, and recent advances in high frequency anodising of Aluminium for improved properties and performance, the current study focuses on the applicability of high frequency pulse anodising of recycled Al alloys. 
The aim is to overcome the detrimental effect in terms of degradation of optical quality and mechanical properties due to higher content of intermetallic phases in the recycled Al alloy. Anodising work is carried out on AA5006 aluminium alloy with high recycled content. Kinetics of anodising under pulse conditions were measured and compared to conventional DC anodising. The optical parameters such as reflected image quality, peak reflection and gloss are measured and correlated to the observed structure and morphology of the films and to the nature of interface between the oxide and the underlying metal.

\section{Experimental}

\subsection{Substrate Preparation}

AA5006 H49 (Novelis WG H4S) aluminium alloys with higher recycled content in a sheet form of $1 \mathrm{~mm}$ thickness was used for the investigation. Composition of the AA5006 alloy is presented in Table 1. All specimens were sanded using 1200 grit SiC paper without lubricant followed by mechanical polishing in the rolling direction. The polished specimens were covered with a protective film prior to cutting into individual samples of 50x40 mm. After cutting to required sizes, the film was removed and surfaces were degreased in a mild alkaline solution $\left(30 \mathrm{~g} / \mathrm{L}\right.$, Alficlean ${ }^{\mathrm{TM}}$, Alufinish, Germany) for 5 minutes. Desmutting was performed by immersing in a $100 \mathrm{~g} / \mathrm{L} \mathrm{HNO}_{3}$ solution for $30 \mathrm{~s}$ followed by rinsing in demineralised water. Finally, the samples were cleaned by ultra-sonication in acetone for 15 min and dried in warm air flow.

\section{Table 1}




\subsection{High Frequency Pulse Anodising}

The polished samples were anodised in a $20 \mathrm{wt} . \%$ sulphuric acid bath kept at constant $18{ }^{\circ} \mathrm{C}$. Sulphuric acid is used because it leaves an optically transparent oxide that is favourable for decorative applications [33]. High frequency square voltage pulses were generated from a function generator (33120A, Agilent). The low powered signal from the function generator was amplified to a high-power signal using a Class-AB power amplifier that secures both current sourcing and sinking. The latter is important for the removal of charges prior to the next pulse cycle. Both voltage and current waveforms were recorded during anodising with the aid of an analogue oscilloscope attached to a data acquisition system.

Two different pulse frequencies were evaluated, i.e. $1 \mathrm{kHz}$ and $5 \mathrm{kHz}$, and compared to reference samples made under traditional DC conditions. Pulses were programmed to have $50 \%$ duty cycle (equal ON and OFF durations) and a zero volt offset at each pulse. The total anodising time was adjusted for each sample to achieve an oxide film layer thickness of $10 \pm 1 \mu \mathrm{m}$. Anodising rates ranged from $0.15 \mu \mathrm{m} / \mathrm{min}$ to $3.47 \mu \mathrm{m} / \mathrm{min}$, meaning that duration for obtaining $10 \mu \mathrm{m}$ ranged from 3 minutes to 65 minutes. Anodic layer thickness was measured using a Fischer Isoscope gauge. After anodising, the samples were rinsed, sealed, and dried. Rinsing was performed in demineralised water for $10 \mathrm{~min}$; hot water sealing for $30 \mathrm{~min}$ in $96{ }^{\circ} \mathrm{C}$ demineralised water; and drying for $5 \mathrm{~min}$ in a $70^{\circ} \mathrm{C}$ oven.

\subsection{Anodising Setup}

Anodising was performed in an a $700 \mathrm{ml}$ anodising cell with $700 \mathrm{~mL}$ volume electrolyte eapacity. The cell is a double walled cell for cooling the electrolyte and to secure constant temperature of the sulphuric acid electrolyte. A magnetic stirrer at $300 \mathrm{rpm}$ secures proper 
circulation of the electrolyte and thus homogenous electrolyte temperature. The entire setup is illustrated in Figure 1.

\section{Figure 1}

\subsection{Optical Characterisation}

Optical appearance after anodising was quantified using a Triple Angle Gloss \& DOI meter (Elcometer 408). This equipment captures the reflected light profiles using a light sensitive array consisting of 512 diodes, and outputs values according to ASTM, DIN and ISO standards (ASTM D523, ASTM D2457, ASTM E430, ASTM D5767, DIN 67530, DIN EN ISO 2813, JIS Z 8741, ISO 7668). The recorded parameters are $20^{\circ}$ gloss, $60^{\circ}$ gloss, peak reflectance and Reflected Image Quality (RIQ). The glossmeter was always positioned parallel to the rolling/polishing direction. Multiple (min. 10) measurements were made for each sample every time moving the glossmeter to a new position. The presented data points are average of at least 10 individual measurements. Any misalignment or sample defect was instantly detected by the reflection curve and the data point was discarded.

\subsection{Microstructural Characterisation}

Test specimens for cross sectional inspection were embedded in cold setting epoxy. The epoxy was cured for 24 hours and then grinded, and polished using diamond paste down to $1 \mu \mathrm{m}$. To reveal the individual grains by Light Optical Microscope (LOM), surface was etched using Keller's reagent for 5 seconds. After LOM analysis, the embedded samples were re-polished with 3 and 1 $\mu \mathrm{m}$ diamonds and then coated with a 2-3nm Au layer by sputtering (Cressington 208HR sputter coater). This procedure allowed for detailed microstructure and surface morphology analysis using 
Scanning Electron Microscopy (Quanta 200 ESEM FEG, FEI) having EDS capability ( $80 \mathrm{~mm}^{2}$ XMax silicen drift detector, Oxford Instruments). The SEM was typically operated at an acceleration voltage of $10 \mathrm{keV}$.

\subsection{Chemical Composition}

The chemical composition of the anodic film was determined by the EDS analysis (Oxford Instruments, $80 \mathrm{~mm}^{2} \mathrm{X}$-max) attached to the SEM (Quanta 200 ESEM FEG, FEI). On the crosssection of the anodised samples, at least 10 measurements were carried out each time analysing an area of $\sim 8 \times 30 \mu \mathrm{m}$.

\subsection{Metal-Oxide Interface Roughness Characterisation}

The metal-oxide interface roughness was determined by stripping the anodic film in a phospho-chromic solution $\left(5 \mathrm{wt} \% \mathrm{H}_{3} \mathrm{PO}_{4}\right.$ and $1.6 \mathrm{wt} \% \mathrm{CrO}_{3} @$ at $90{ }^{\circ} \mathrm{C}$ ) [34] followed by the analysis using Atomic Force Microscopy (AFM). The instrument used was a NX20 from Park system. This AFM has a linearised Z-scanner (approximately $8 \mu \mathrm{m}$ dynamic range) which is decoupled from the feedback-controlled lateral XY-translation stage (approximately $100 \mu \mathrm{m} \times 100$ $\mu \mathrm{m}$ scan range). The probing tip had a radius of approximately $7 \mathrm{~nm}$. In order to minimise wear on both the probing tip and the surface, the intermittent scanning mode was used and the probe oscillated at its resonance frequency of approximately $300 \mathrm{kHz}$. This reduces the time of physical contact between tip and sample significantly and also reduces any lateral forces during the scan. An area of $50 \times 50 \mu \mathrm{m}$ at a resolution of $1024 \times 1024$ pixels was scanned for subsequent analysis using SPIP software (Scanning Probe Image Processor). Raw data was corrected by using plane and linewise levelling in SPIP, before calculating Ra values for all the 1024 scan lines. The presented Ra values are averaged from all 1024 lines. 


\section{Results}

\subsection{Anodic Film Growth Rate}

\section{Figure 2}

The voltage-current response during HF pulse anodising has previously been investigated. Jensen et. al. [27] showed that pulsing from zero to $15 \mathrm{~V}$ at $1 \mathrm{kHz}$, results in very dramatic current peak of approximately $30 \mathrm{~A} / \mathrm{dm}^{2}$. As soon as the barrier layer is fully charged (during one pulse cycle), the current drops to approximately $4 \mathrm{~A} / \mathrm{dm}^{2}$; i.e. many times lower than the peak current. As soon as the voltage is lowered from $15 \mathrm{~V}$ to zero, barrier layer charges are removed, which results in a large negative peak current. The negative peak is followed by a plateau of zero amperes, before the next positive cycle is applied. The pulse frequencies and voltages mentioned by Jensen et. al. [27] are identical to those used in the present work.

Figure 2 shows the effect of anodising pulse frequency on the anodic film growth rate. Results show that use of $5 \mathrm{kHz}$ provided faster kinetics compared to $1 \mathrm{kHz}$ frequency. DC anodising presents the slowest condition in the voltage interval between 10 and $15 \mathrm{~V}$. However, once exceeding $15 \mathrm{~V}$, DC kinetics kinetics at direct currents increase dramatically and exceed the 
rate for $1 \mathrm{kHz}$ pulse anodising. At $20 \mathrm{~V}$, the anodising speed reaches approximately $3 \mu \mathrm{m} / \mathrm{min}$ for both DC and $5 \mathrm{kHz}$, which is considered a very fast growth rate. The faster eptimised kinetics of 5 $\mathrm{kHz}$ anodising led to the investigation of voltage levels below $10 \mathrm{~V}$. The growth rate is observed to gradually decrease with decreasing voltage level, finally reaching a growth rate of $0.17 \mu \mathrm{m} / \mathrm{min}$ at 4 V.

\subsection{Optical Characterisation - Influence of Voltage and Frequency}

The calculated gloss values are presented in Figure 3. Focusing on the interval between $10 \mathrm{~V}$ and $20 \mathrm{~V}$, results show that increasing voltage gives a less glossy surface for all anodising conditions. The decrease in gloss from $10 \mathrm{~V}$ to $15 \mathrm{~V}$ is most severe for traditional DC anodising, where pulse anodising seems to have almost identical values for both $10 \mathrm{~V}$ and $15 \mathrm{~V}$. Only when increasing the voltage to $20 \mathrm{~V}$, the gloss level drops for the pulse anodising to a value similar to DC conditions. The 60 degree gloss is strongly affected by the voltage level for the DC conditions, whereas pulsing at $1 \mathrm{kHz}$ and $5 \mathrm{kHz}$ provides higher values all the way up to $20 \mathrm{~V}$. Specular reflection data have almost similar trend as the 20 degree gloss, with gloss levels decreasing rapidly under increasing the DC voltages. The trend is much less pronounced for the pulse mode, but finally decreases to the same level as DC when the voltage extends to $20 \mathrm{~V}$. A similar behaviour is found for Reflected Image Quality (RIQ). A non-anodised reference sample shows gloss values $\left(20^{\circ}\right.$ gloss) in excess of 1100 G.U. which is almost 3 times higher than the surface gloss obtained under optimal anodising conditions. Optical data for the reference sample are not included in Figure 3 due to distinctly higher values, which would compromise clarity of voltage dependency.

Finding that almost all optical parameters improve with decreasing anodising voltage (in the range from $10-20 \mathrm{~V}$ ), it was decided to decrease the anodising voltage below $10 \mathrm{~V}$. This became realistic for $5 \mathrm{kHz}$ due to the improved kinetics behaviour, as stated previously. The voltage was 
decreased in steps of $2 \mathrm{~V}$ finding that the minimum anodising rate is close to $4 \mathrm{~V}$. Decreasing the voltage even further, does not allow for water electrolysis, meaning that no aluminium oxide will be formed. Optical characterisation was performed in a comparable manner as the 10-20 V samples with data also presented in Figure 3. It is interesting to find that both gloss and specular reflection decrease as soon as the anodising voltage is reduced below $10 \mathrm{~V}$ finally reaching optical properties that are only found at $20 \mathrm{~V}$. As such, the parabolic trend for 20 degree gloss and specular reflection suggests a peak close to $10 \mathrm{~V}$. The parabolic peak for RIQ values is slightly shifted towards the lower voltage side suggesting that $8 \mathrm{~V}$ could be the optimum.

\section{Figure 3}

\subsection{Optical Characterisation - Influence of anodic film thickness}

Figure 4 presents the relationship between specular reflection and film thickness for specimens anodised at 4, 6, 8 and $10 \mathrm{~V}$. Specular reflection shows a linear variation in the range from 5-10 $\mu \mathrm{m}$ for all voltage levels. A $4 \mathrm{~V}$ anodising yields the lowest values; $6 \mathrm{~V}$ being better, but $8 \mathrm{~V}$ and $10 \mathrm{~V}$ presenting almost equally high specular reflection values.

\section{Figure 4}

\subsection{Microstructural Investigation}




\section{Figure 5}

The Light Optical Microscope (LOM) images presented in

Figure 5 show a polished and etched surface of AA5006, which shows the high level of intermetallic phases. The intermetallic phases differ in physical size up to approximately $10 \mu \mathrm{m}$ in length.

Figure 6 shows the SEM images of the cross section of the samples anodised at $15 \mathrm{~V}$-DC and $15 \mathrm{~V}-1 \mathrm{kHz}$. These two samples present large differences in optical reflection values, therefore selected for SEM study to investigate the microstructural differences in the anodic film. The images in Figure 6 show the general overview with intermetallic particles in the aluminium, but not in the anodic film. Large number of cavities are observed throughout the anodic film, presumably due to the oxidation of the intermetallic phased and subsequent dissolution.

\section{Figure 6}

\subsection{Composition of Anodic Film}

Average composition of the anodic film from the Cross-sectional EDS analysis is show in Figure 7. Iron level ranges between $0.05-0.1 \mathrm{wt} . \%$, silicon between $0.05-0.11$ wt.\% and manganese between $0.15-0.22$ wt. $\%$, however, no obvious trend is observed between element composition and anodising parameters such as the voltage amplitude and frequency. Also, no difference in composition was observed between samples anodised at DC compared to samples that are anodised in high frequency pulse mode. Only sulphur content was changed with anodising parameters both for the DC and HF pulse anodising. 


\section{Figure 7}

\subsection{Metal-oxide Interface Roughness}

The anodic films of the individual specimens were treated in a phospho-chromic solution to secure that the anodic film is stripped, but the underlying aluminium surface is preserved.

Figure 8 shows the topography of the surface from AFM analysis for the $15 \mathrm{~V}$-DC and $15 \mathrm{~V}$ $1 \mathrm{kHz}$ specimens. The images show peaks and valleys across the surface as well as indentations/cavities at locations of the intermetallic particles. Although the Ra values of these two specimens are largely different, no systematic changes are found in surface topography. This suggests that the intermetallic particles behave in a similar manner regardless if anodising is conducted by DC or by HF pulsing, and that the differences in surface roughness are not related to intermetallic response.

The averaged Ra-values from the AFM characterisation are presented in Figure 9 as a function of the anodising conditions. Surface roughness generally increases with increasing anodising voltage and the highest values are found for the traditional DC anodising. The 10V-DC creates a metal-oxide interface roughness of $50 \mathrm{~nm}$, which increases to almost $100 \mathrm{~nm}$ when anodising at 20V-DC. A similar large interface roughness is not found for neither $1 \mathrm{kHz}$ or $5 \mathrm{kHz}$ samples with values ranging from $36 \mathrm{~nm}$ to $52 \mathrm{~nm}$. A polished and non-anodised reference sample showed $20 \mathrm{~nm}$ roughness (Figure 9), which is typical of such surfaces [35].

\section{Figure 8}

\section{Figure 9}


To find the correlation between metal-oxide interface roughness and anodised optical appearance, surface roughness data from Figure 9 are compared to gloss data from Figure 3 and presented in Figure 10. Gloss data, peak reflection and Reflected Image Quality (RIQ) are plotted as a function of interface roughness. It important to mention that the optical values are recorded when the anodic film is present on the sample, while the roughness data are presented for the phosphochromic stripped surface. Focusing on the relationship between interface roughness and $60^{\circ}$ gloss, there seems to exist an almost linear relationship that includes data from all three anodising voltages $(10,15$ and $20 \mathrm{~V})$. In this case, $60^{\circ}$ gloss drops linearly with increasing surface roughness. Also, when focusing on $20^{\circ}$ gloss, there is a linear relationship between peak reflectance and RIQ as a function of interface roughness.

\section{Figure 10}

\section{Discussion}

\subsection{Anodic Film Growth Rate \& Optical Effects}

Sheasby et al. [1] have previously reported how anodic film growth rate increases exponentially with increasing anodising voltage until the current density reaches the level required for electrical arcing across the alumina barrier layer causing a fatal destruction. The present study confirms the exponential growth rate as a function of increasing anodising voltage potentiat. This is true for both Direct Current (DC) and High Frequency Pulse Anodising, with the latter generally presenting improved kinetics compared to DC (Figure 2). The improved kinetics at increasing frequency allows for anodising at voltages below $10 \mathrm{~V}$. These low voltages are traditionally not recommendable for DC anodising due to prolonged exposure to the acid electrolyte, which will risk 
pore wall attack resulting in a soft oxide film. A soft oxide film will compromise both corrosion and mechanical properties [1]. Pulse anodising at $\underline{4 \mathrm{~V}}-5 \mathrm{kHz}$ yields a growth rate of $0.17 \mu \mathrm{m} / \mathrm{min}$, which is still higher than $10 \mathrm{~V}-\mathrm{DC}$ of $0.15 \mu \mathrm{m} / \mathrm{min}$.

In general it is found that the optical properties of anodised AA5006 finds an optimum close to $10 \mathrm{~V}$. Additionally, there is very little optical difference between DC and HF pulse anodising at this specific voltage level (see Figure 3), which shows that pulse anodising offers little advantages for optimising the aesthetic appearance of recycled AA5006. At this voltage level, the single identified advantage of pulse anodising is the faster growth rate compared to DC. The latter is especially true for $15 \mathrm{~V}$ anodising, where the optical properties are just as good as $10 \mathrm{~V}$-DC, but with a growth rate more than 5 times higher. From Figure 4, it is observed that the specular reflection is linearly dependent on film thickness in the range from 5-10 $\mu \mathrm{m}$ for all voltage levels. This is in agreement with the reported work of Cooke et al. [36] showing that increasing film thickness has a negative impact on the optical appearance. The drop in specular reflection as a function of film thickness emphasises the importance of having identical film thickness for all test specimens in order to conclude on differences in anodising parameters.

\subsection{Microstructural and Compositional Effects on Optical Properties}

Focusing on the lower part of the anodic films presented in Figure 6 (i.e. the region close to the metal-oxide interface), no partially oxidised particles are found. Rather, the intermetallic particles appear entirely absent, which presumably is a result of particle oxidation followed by chemical dissolution. This suggests that the oxidation rate of the intermetallics is faster than the oxidation rate of aluminium. Further, the absence of any intermetallics within the anodic films, suggests a fast dissolution of the intermetallics.

High magnification SEM images of samples anodised at DC and HF pulses show how the intermetallic particles only have caused minors distortion to the metal-oxide interface planarity. 
Previous studies [37-39] have revealed that embedded particles can act as current thieves during DC anodising, and thus create significant distortion to the flatness of the metal-oxide interface. The non-flat interface will affect the reflection of light from the metal-oxide interface, especially compromising the reflected image clarity [36]. The current thieving phenomenon is due to the parasitic oxygen evolution at the location of the intermetallic particle at the surface of the anodised specimen [36,40-42]. The local current level at these particle sites will affect the anodising current at the nearby aluminium regions, causing a slower aluminium-to-alumina oxidation compared to the regions farther away from the particle. This means that the interface planarity may become compromised when particles are present in the aluminium alloy, with the risk of light becoming scattered in multiple directions [36]. Considering that HF pulse anodising has a 50\% off cycle, as opposed to $100 \%$ duty cycle for DC operation, it is highly probable that kinetics for the oxygen reduction process at the intermetallic particles is affected. Assuming that kinetics are lowered (because of the lower duty cycle) it would affect the current ratio of the two reactions that can take place at the anode. This would effectively alter the current thieving conditions and thus affect the interface planarity. However, upon visual observation of AA5006 after DC and High Frequency Pulse mode, no oxygen gas evolution is observed at the anode. In fact, this observation suggests that little or no current thieving of the intermetallic particles take place that potentially could affect the interface planarity due to this mechanism.

The SEM images presented in Figure 6 indicate that the intermetallics have fully oxidised during the anodising process, which fits well with previously reported data [43]. Timm et al. [43] categorizes $\mathrm{Al}_{12}(\mathrm{Fe}, \mathrm{Mn})_{3} \mathrm{Si}$ particles as type $\mathrm{B}$ or $\mathrm{C}$, defined as particles that are either "oxidised and incorporated at a rate comparable or slower than Al" or "oxidised and incorporated at a rate faster than Al'". Whether the particle acts as a type B or C, depends on the physical size of the 
particle [43]. Anodising in DC and HF pulse anodising results presented in this study suggest that the intermetallic particles present in AA5006 act as type C.

Data in Figure 7 show no obvious trend between film composition and the anodising parameters such as voltage amplitude and frequency. The only identified difference was found in the sulphur level, where it becomes evident that the sulphur increases with increasing anodising voltage both for DC and HF pulse anodising. Sulphur deposition originates from the anodising process, where the sulfate anions are attracted to the positively charged electrode. Therefore, an increase in voltage effectively increase the migration of sulfate ions to anode and deposition.

\subsection{Metal-oxide interface roughness}

AFM mapping of the metal-oxide interface presented in Figure 8 shows that no anodising conditions create a surface with protruding intermetallics rather than depressions from the intermetallics. This indicates that the change of surface roughness according to data in Figure 9 mainly are related to the $\mathrm{Al}-\mathrm{Al}_{2} \mathrm{O}_{3}$ interface roughness and not to changes in e.g. intermetallic dissolution.

Data in Figure 10 showing the relationship between Reflected Image Quality (RIQ) and interface roughness, indicate that the data sets from 10,15 and $20 \mathrm{~V}$ do not coincide. This means that the same Ra value can result in distinctly different optical appearance values. For example, RIQ data at an interface roughness value of $\mathrm{Ra}=50 \mathrm{~nm}$ can either be 10,50 or 70 depending on the voltage that is used during anodising $(10,15,20 \mathrm{~V})$. This clearly illustrates the complexity of surface roughness of the interface and light interaction. Nevertheless, the reasonably well-fitting data within the same data group suggests that the optical appearance of both DC and HF pulse anodising is strongly dependent on the resultant microstructure in the interface region between aluminium and aluminium 
oxide. Targeting a decorative appearance with high gloss, high peak reflectance and good reflected image clarity, it is important to use anodising parameters that yield a smooth and non-defective interface roughness. For all anodising conditions, it is found that an increase in interface roughness will results in degradation of optical properties.

\section{Conclusion}

The basic characteristics during High Frequency pulse anodising of aluminium alloy AA5006 have been investigated and compared to traditional DC anodising in sulphuric acid. Firstly, the kinetics were found to depend on frequency and voltage level. Secondly, the optical properties were also found to depend on voltage and frequency, and generally found to improve when using HF pulse compared to DC. Additional conclusions are:

- Intermetallic particles, mainly consisting of $\mathrm{Al}, \mathrm{Si}, \mathrm{Fe}$ and $\mathrm{Mn}$, are oxidised and largely dissolved during the course of anodising. No differences are found for DC and HF pulse mode.

- Composition of the anodic films are largely independent on anodising voltage and frequency. Only Sulphur content, originating from the electrolyte, is influenced by anodising voltage, however, remains independent on frequency level.

- Metal-oxide interface roughness was found to depend on both voltage and frequency. In general, low interface roughness is favoured by decreasing voltage and increasing pulse frequency.

- A good correlation is found between the optical properties and interface roughness. Due to this good correlation, it is argued that the main mechanism behind the improved optical 
properties, lies in the fact that HF pulse anodising yields a smoother interface than traditional DC anodising.

\section{Acknowledgements}

- The authors would like to thank Innovation Fund Denmark for their financial support of Industrial PhD Flemming Jensen (Grant No. 5016-00128B).

- The work has been supported by funds from the Danish Agency for Institutions and Educational Grants.

7 Data Availability

The raw/processed data required to reproduce these findings cannot be shared at this time due to technical or time limitations.

\section{References}

[1] P.G. Sheasby, R. Pinner, S. Wernick, The surface treatment and finishing of aluminium and its alloys v. 2, ASM International, 2001.

[2] C.A. Grubbs, Anodizing of aluminum, Met. Finish. 105 (2007) 397-412. doi:10.1016/S00260576(07)80359-X.

[3] C.A. Grubbs, Decorative and architectural anodizing, Met. Finish. 93 (1995) 449-459. doi:10.1016/0026-0576(95)93394-H.

[4] N. Tabrizian, H.N. Hansen, P.E. Hansen, R. Ambat, P. Møller, Influence of annealing and deformation on optical properties of ultra precision diamond turned and anodized 6060 aluminium alloy, Surf. Coatings Technol. 204 (2010) 2632-2638. 
doi:10.1016/j.surfcoat.2010.02.002.

[5] A.K. Mukhopadhyay, A.K. Sharma, Influence of Fe-bearing particles and nature of electrolyte on the hard anodizing behaviour of AA 7075 extrusion products, Surf. Coatings Technol. 92 (1997) 212-220. doi:10.1016/S0257-8972(97)00102-3.

[6] M. Saenz de Miera, M. Curioni, P. Skeldon, G.E. Thompson, The behaviour of second phase particles during anodizing of aluminium alloys, Corros. Sci. 52 (2010) 2489-2497. doi:10.1016/j.corsci.2010.03.029.

[7] H. Habazaki, K. Shimizu, P. Skeldon, G.E. Thompson, G.C. Wood, X. Zhou, Effects of alloying elements in anodizing of aluminium, Trans. Inst. Met. Finish. 75 (1997) 18-23.

[8] M. Aggerbeck, S. Canulescu, K. Dirscherl, V.E. Johansen, S. Engberg, J. Schou, R. Ambat, Appearance of anodised aluminium: Effect of alloy composition and prior surface finish, Surf. Coatings Technol. 254 (2014) 28-41. doi:10.1016/j.surfcoat.2014.05.047.

[9] P.G. Sheasby, R. Pinner, The Surface Treatment and Finishing of Aluminium and Its Alloys, Volume 2, 6th ed., ASM International; Finishing Publications, 2001.

[10] R. Akeret, H. Bichsel, E. Schwall, E. Simon, M. Textor, The Influence of chemical composition and fabrication procedures on the properties of anodised aluminium surfaces, Trans. IMF. 68 (1990) 20-28. doi:10.1080/00202967.1990.11870860.

[11] S. Van Gils, S. Holten, E. Stijns, M. Vancaldenhoven, H. Terryn, L. Mattsson, Electropolishing of aluminium: processing and assessment of visual appearance, Surf. Interface Anal. 35 (2003) 121-127. doi:10.1002/sia.1477.

[12] M. Saito, Y. Shiga, M. Miyagi, K. Wada, O. Sachiko, Optical Transmittance of Anodically Oxidized Aluminum Alloy, Jpn. J. Appl. Phys. 34 (1995) 3134. 
[13] A.W. Brace, Hard anodising of aluminium and its alloys, Electroplating. 7 (1954). https://findit.dtu.dk/en/catalog/2362344502 (accessed September 17, 2018).

[14] J. Rasmussen, Pulse anodizing of aluminium alloys in sulphuric acid, Proc. Aesf Annu. Tech. Conf. (1993). http://findit.dtu.dk/en/catalog/2364306702 (accessed June 5, 2018).

[15] K. Okubo, S. Suyama, Y. Sakura, Studies of Microstructure of Anodic Oxide Films on Aluminum by Pulse Current with a Negative Component, J. Surf. Finish. Soc. Japan. 40 (1989) 1366-1371. doi:10.4139/sfj.40.1366.

[16] A. Deacon Juhl, Pulse anodising of extruded and cast aluminium alloys, Technical University of Denmark, 1999.

[17] K. Yokoyama, H. Konno, H. Takahashi, M. Nagayama, Advantages of Pulse Anodizing, Plat. Surf. Finish. 69 (1982) 62-65.

[18] V. Raj, M.R. Rajaram, G. Balasubramanian, S. Vincent, D. Kanagaraj, Pulse Anodizing - An Overview, Trans. Inst. Met. Finish. 81 (2003) 114-121.

[19] M. Bononi, R. Giovanardi, A. Bozza, P. Mattioli, Pulsed current effect on hard anodizing process of 2024-T3 aluminium alloy, Surf. Coatings Technol. 289 (2016) 110-117. doi:10.1016/j.surfcoat.2016.01.056.

[20] Pulse Anodizing Process, Met. Finish. 96 (1998) 84. doi:10.1016/S0026-0576(98)80711-3.

[21] J. Rasmussen, Pulse anodizing of aluminum: The recovery effect, Plat. Surf. Finish. 89 (2002). http://findit.dtu.dk/en/catalog/9834874 (accessed June 5, 2018).

[22] T. Yamamoto, H. Tanaka, M. Fujita, H. Asoh, S. Ono, Effect of high-frequency switching electrolysis on film thickness uniformity of anodic oxide film formed on AC8A Aluminum alloy, J. Japan Inst. Light Met. 60 (2010) 602-607. doi:10.2464/jilm.60.602. 
[23] V.C. Gudla, F. Jensen, K. Bordo, A. Simar, R. Ambat, Effect of High Frequency Pulsing on the Interfacial Structure of Anodized Aluminium-TiO2, J. Electrochem. Soc. 162 (2015) C303-C310. doi:10.1149/2.0311507jes.

[24] V.C. Gudla, K. Bordo, F. Jensen, S. Canulescu, S. Yuksel, A. Simar, R. Ambat, High frequency anodising of aluminium-TiO2 surface composites: Anodising behaviour and optical appearance, Surf. Coatings Technol. 277 (2015) 67-73. doi:10.1016/j.surfcoat.2015.07.035.

[25] V.C. Gudla, F. Jensen, A. Simar, R. Shabadi, R. Ambat, Friction stir processed Al-TiO2 surface composites: Anodising behaviour and optical appearance, Appl. Surf. Sci. 324 (2015) 554-562. doi:http://dx.doi.org/10.1016/j.apsusc.2014.10.151.

[26] V.C. Gudla, K. Bordo, S. Engberg, K. Rechendorff, R. Ambat, High frequency pulse anodising of magnetron sputtered Al-Zr and Al-Ti Coatings, Mater. Des. 95 (2016) 340-347. doi:10.1016/j.matdes.2016.01.091.

[27] F. Jensen, V.C. Gudla, I. Kongstad, R. Ambat, High frequency pulse anodising of aluminium: Anodising kinetics and optical appearance, Surf. Coatings Technol. 360 (2019) 222-231. doi:10.1016/j.surfcoat.2018.12.117.

[28] M. Aggerbeck, A. Junker-Holst, D.V. Nielsen, V.C. Gudla, R. Ambat, Anodisation of sputter deposited aluminium-titanium coatings: Effect of microstructure on optical characteristics, Surf. Coatings Technol. 254 (2014) 138-144. doi:10.1016/j.surfcoat.2014.05.073.

[29] V.C. Gudla, S. Canulescu, R. Shabadi, K. Rechendorff, K. Dirscherl, R. Ambat, Structure of anodized Al-Zr sputter deposited coatings and effect on optical appearance, Appl. Surf. Sci. 317 (2014) 1113-1124. doi:10.1016/j.apsusc.2014.09.037.

[30] V.C. Gudla, S. Canulescu, R. Shabadi, K. Rechendorff, J. Schou, R. Ambat, Anodization and 
Optical Appearance of Sputter Deposited Al-Zr Coatings, in: J. Grandfield, TMS (Eds.), Light Met. 2014, John Wiley \& Sons, Inc., 2014: pp. 369-373. doi:10.1002/9781118888438.ch63.

[31] E. Senel, M. Hallenstvet, Effect of Alloying Elements on the Colour Development of Anodised Al-Mg-Si Alloys, Mater. Sci. Forum. 794-796 (2014) 247-252. doi:10.4028/www.scientific.net/MSF.794-796.247.

[32] L.F. Mendes, A.S. Moraes, J.S. Santos, F.L. Leite, F. Trivinho-Strixino, Investigation of roughness and specular quality of commercial aluminum (6061 alloy) for fabrication of nanoporous anodic alumina films, Surf. Coatings Technol. 310 (2017) 199-206. doi:10.1016/j.surfcoat.2016.12.068.

[33] J.M. Runge, The Metallurgy of Anodizing Aluminum, Springer International Publishing, Cham, 2018. doi:10.1007/978-3-319-72177-4.

[34] MILITARY SPECIFICATION FOR ALUMINUM AND ALUMINUM ALLOYS, MIL-A8625F, Section 4.5.2.1, (n.d.). http://www.iaindy.com/Documents/8625F.pdf.

[35] V.C. Gudla, V.E. Johansen, S. Canulescu, J. Schou, R. Ambat, Simulation of reflectance from white-anodised aluminium surfaces using polyurethane???TiO2 composite coatings, J. Mater. Sci. 50 (2015) 4565-4575. doi:10.1007/s10853-015-9005-1.

[36] W.E. Cooke, Factors Affecting Loss of Brightness and Image Clarity During Anodizing of Bright Trim Aluminium Alloys in Sulfuric Acid Electrolyte, Plating. (1962) 1157-1164.

[37] J.M. Montero-Moreno, M. Sarret, C. Müller, Self-ordered porous alumina by two-step anodizing at constant current: Behaviour and evolution of the structure, Microporous Mesoporous Mater. 136 (2010) 68-74. doi:10.1016/j.micromeso.2010.07.022.

[38] J.C. Walmsley, C.J. Simensen, A. Bjørgum, F. Lapique, K. Redford, The Structure and 
Impurities of Hard DC Anodic Layers on AA6060 Aluminium Alloy, J. Adhes. 84 (2008) 543-561. doi:10.1080/00218460802161590.

[39] K. Shimizu, G.. Brown, K. Kobayashi, P. Skeldon, G.. Thompson, G.. Wood, Ultramicrotomy — a route towards the enhanced understanding of the corrosion and filming behaviour of aluminium and its alloys, Corros. Sci. 40 (1998) 1049-1072. doi:10.1016/S0010-938X(98)00006-7.

[40] H. Habazaki, H. Konno, K. Shimizu, S. Nagata, P. Skeldon, G.. Thompson, Incorporation of transition metal ions and oxygen generation during anodizing of aluminium alloys, Corros. Sci. 46 (2004) 2041-2053. doi:10.1016/j.corsci.2003.10.027.

[41] X. Zhou, H. Habazaki, K. Shimizu, P. Skeldon, G.E. Thompson, G.C. Wood, Formation and accommodation of gold atom clusters and oxygen bubbles during amorphous anodic alumina growth, Proc. R. Soc. A Math. Phys. Eng. Sci. 455 (1999) 385-399.

doi:10.1098/rspa.1999.0318.

[42] K. SHIMIZU, H. HABAZAKI, P. SKELDON, G. THOMPSON, G. WOOD, Role of metal ion impurities in generation of oxygen gas within anodic alumina, Electrochim. Acta. 47 (2002) 1225-1228. doi:10.1016/S0013-4686(01)00836-2.

[43] J. Timm, Influence of Fe and Si Containing Phases on the Anodisation Behaviour, Key Eng. Mater. 44-45 (1990) 219-232. doi:10.4028/www.scientific.net/KEM.44-45.219. 
Table 1 - Chemical composition limits for the investigated alloys in wt.\%. [31]

$\begin{array}{lllllllll}\mathrm{Si} & \mathrm{Fe} & \mathrm{Cu} & \mathrm{Mn} & \mathrm{Mg} & \mathrm{Cr} & \mathrm{Zn} & \mathrm{Ti} & \mathrm{Al}\end{array}$

AA5006 Max 0.4 Max

Max 0.1 $0.4-0.8 \quad 0.8-1.3 \quad \operatorname{Max} 0.1 \quad \operatorname{Max} \quad \operatorname{Max}$

0.8

$0.25 \quad 0.1$

Bal. 
Figure 1: High frequency pulse anodising setup

Figure 2: Anodic film growth rate for AA5006 as a function applied voltage under DC and high frequency pulse anodising conditions.

Figure 3 : Optical characterisation of polished and $10 \mu \mathrm{m}$ anodised AA5006. (a) 20 degree Gloss data, (b) 60 degree Gloss data, (c) specular reflection, (d) reflected image quality.

Figure 4 : Peak reflection of $5 \mathrm{kHz}$ anodised AA5006 with different oxide film thicknesses.

Figure 5: Light optical microscopy of polished AA5006 in cross section. Etched in Keller's reagent for 5 s. (a) 200x magnification, (b) 1000x magnification.

Figure 6: SEM-ETD cross section images of anodised AA5006 at 5.000 and $10.000 \mathrm{X}$ low and high magnification. Anodising conditions are 15V-DC and 15V-1kHz. Anodic film thickness of $15 \mathrm{~V}-$ DC sample is $10,6 \mu \mathrm{m}$ and $11,0 \mu \mathrm{m}$ for $15 \mathrm{~V}-1 \mathrm{kHz}$.

Figure 7: Measured concentration of Silicon, Manganese, Iron and Sulphur in anodic films formed at three different voltages and three different frequencies using SEM-EDS.

Figure 8: AFM imaging of the metal-oxide interface. (a) $15 \mathrm{~V}-\mathrm{DC}$, (b) $15-1 \mathrm{kHz}$

Figure 9: Surface roughness of phospho-chromic acid stripped surface. Ra -value as function of anodising voltage and frequency

Figure 10: Correlation between optical properties and metal-oxide interface roughness. (a) 20 degree gloss, (b) 60 degree gloss, (c) specular reflection, and (d) Reflected image quality 


\section{Highlights:}

- High Frequency Pulse anodising is faster than conventional DC anodising.

- High Frequency Pulse anodising improves surface gloss for AA5006

- Intermetallic particles are oxidised and largely dissolved during anodising

- Composition of the anodic films are independent on anodising voltage and frequency

- A good correlation is found between the optical properties and interface roughness 


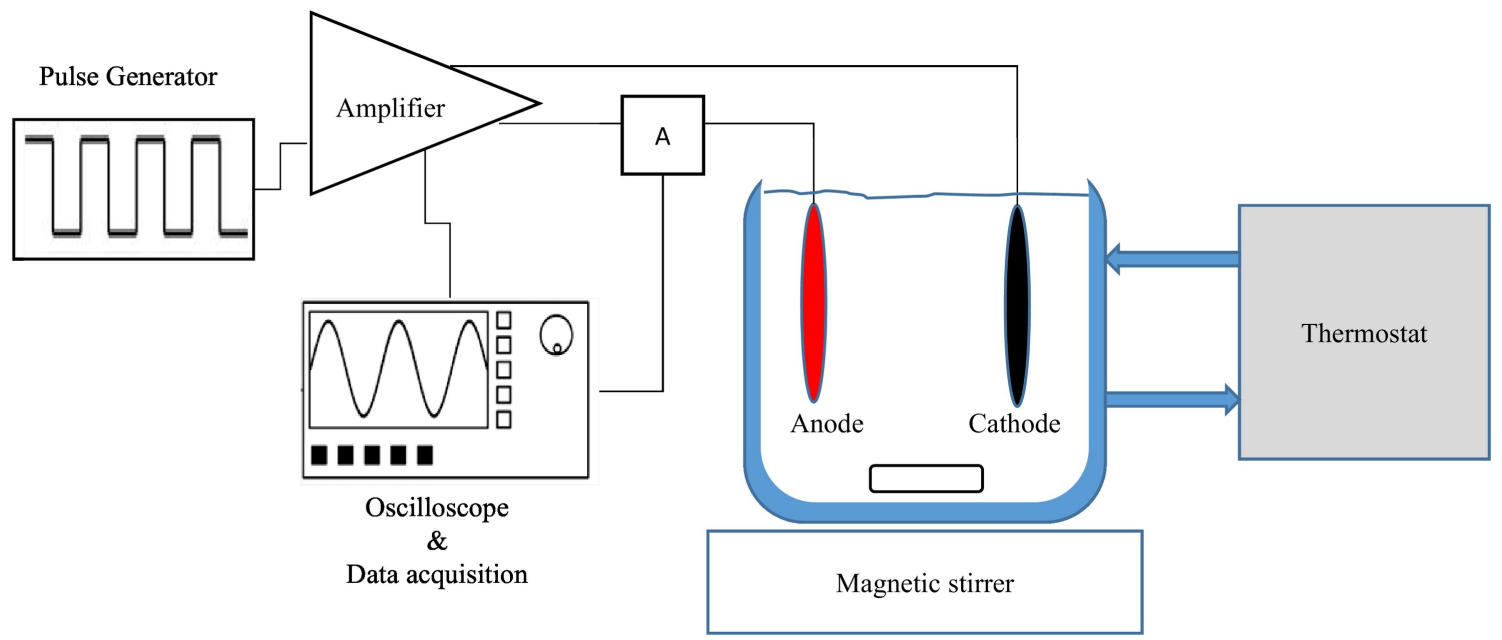

Figure 1 


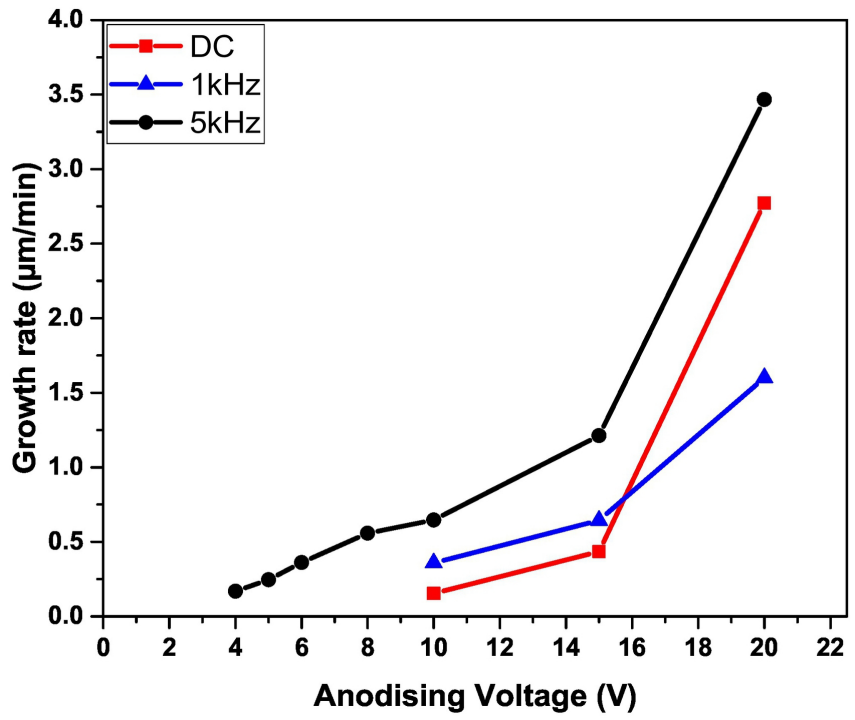

Figure 2 


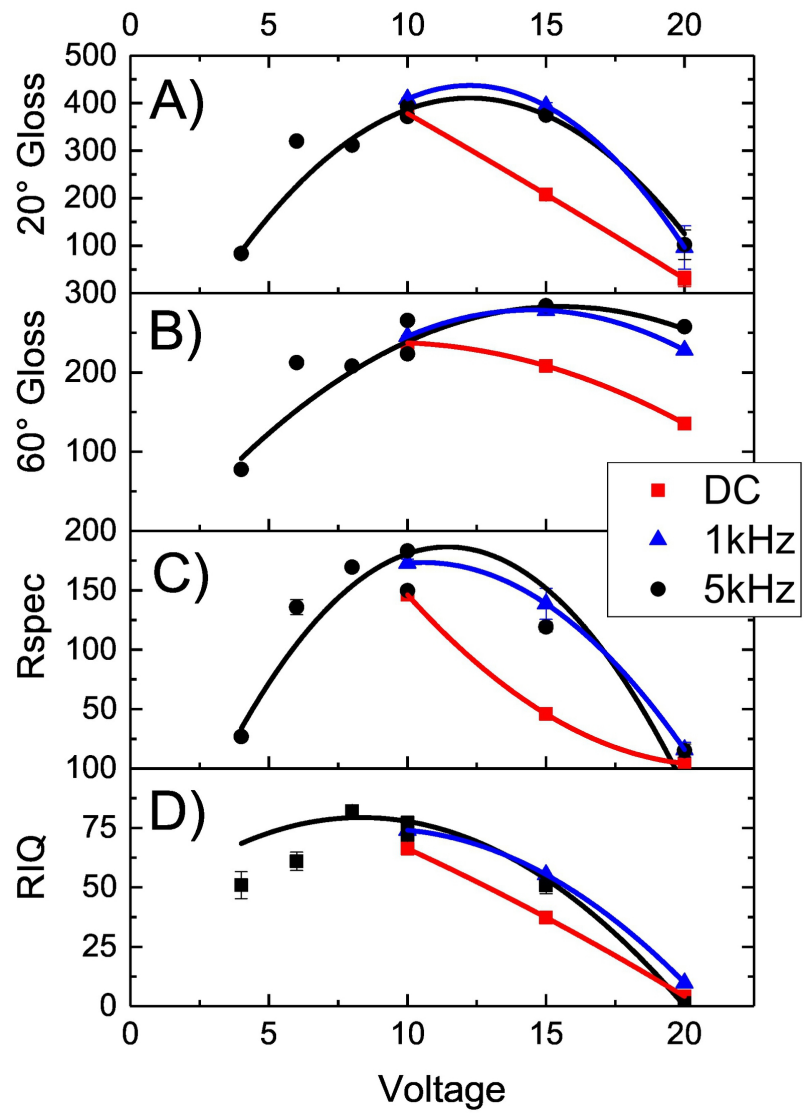

Figure 3 


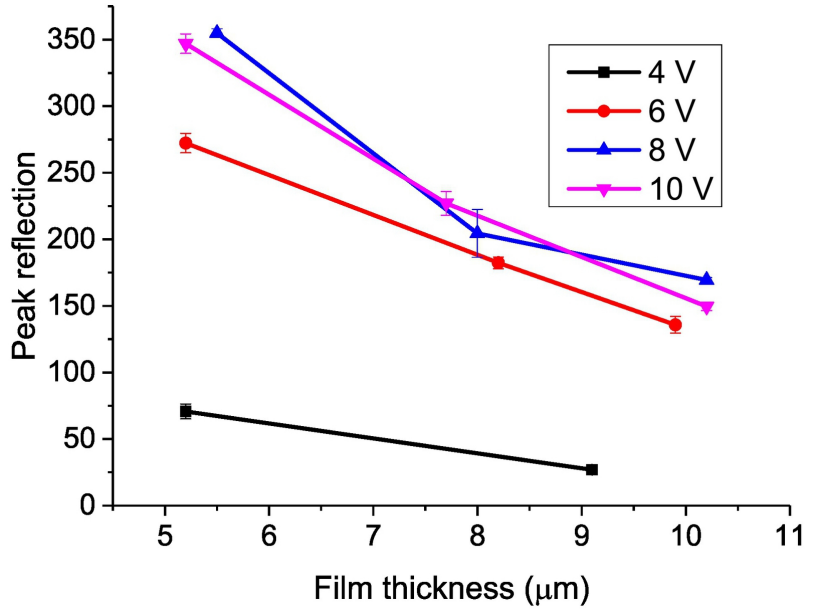

Figure 4 
$100 \mu \mathrm{m}$

Figure 5 


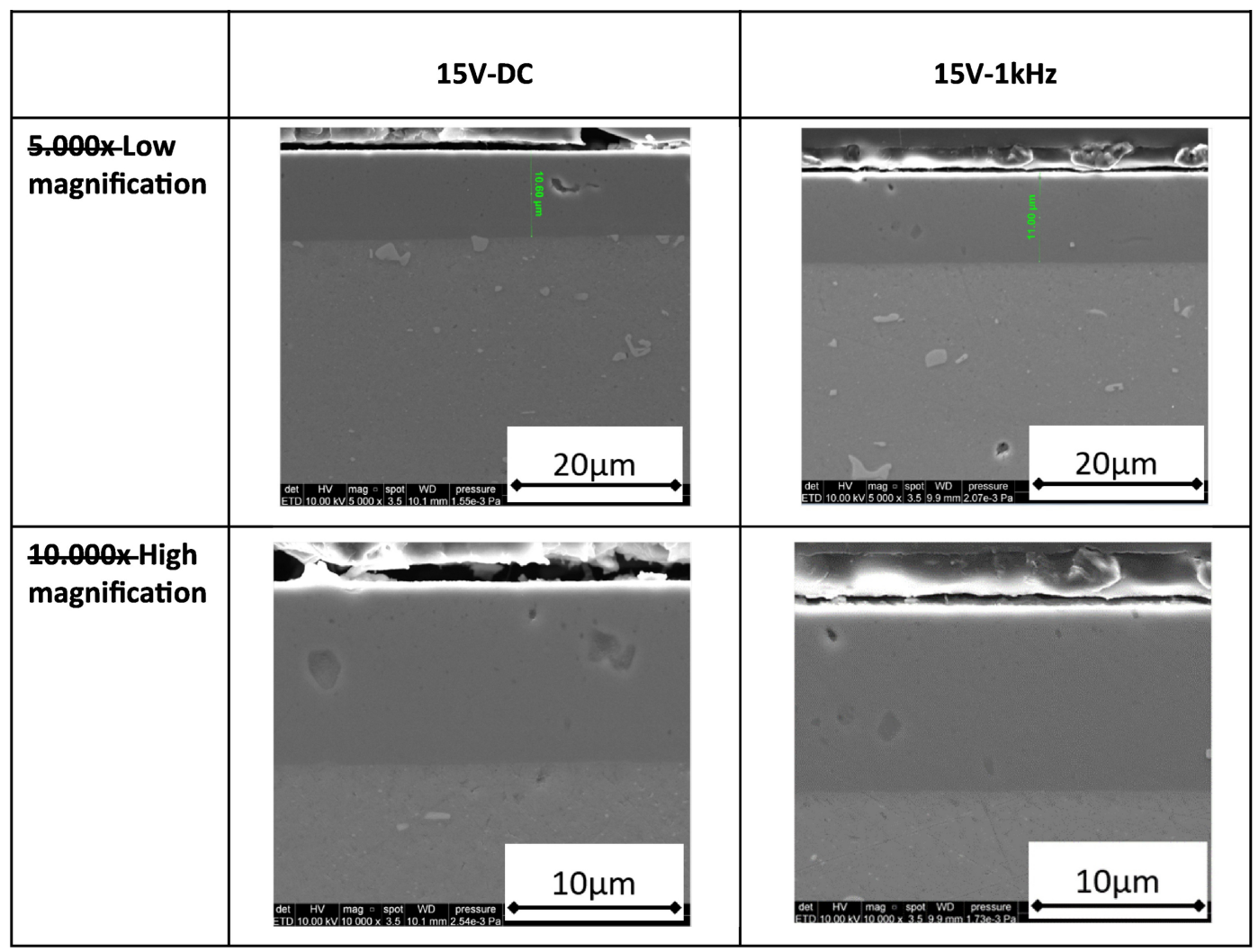

Figure 6 


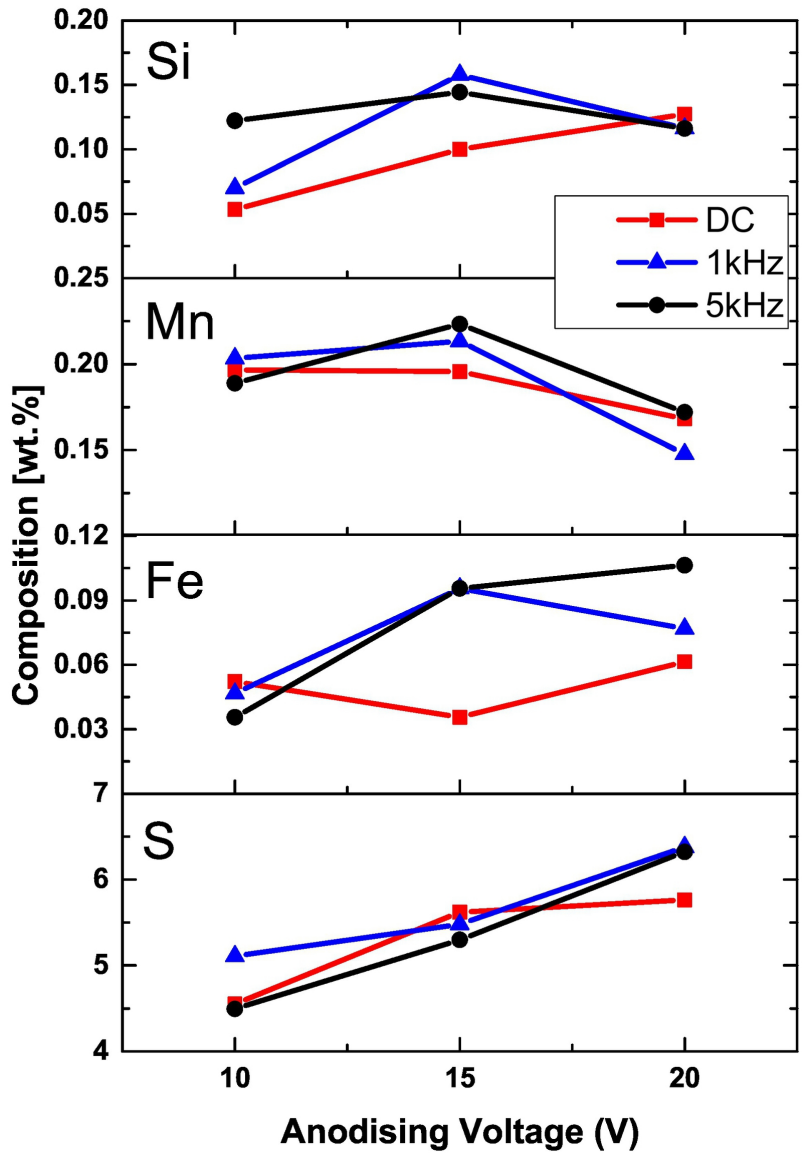

Figure 7 


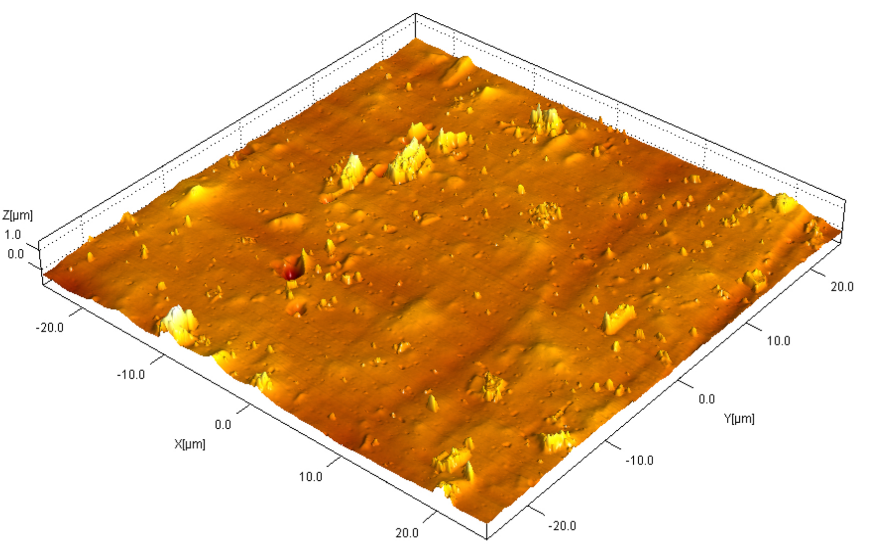

(a)

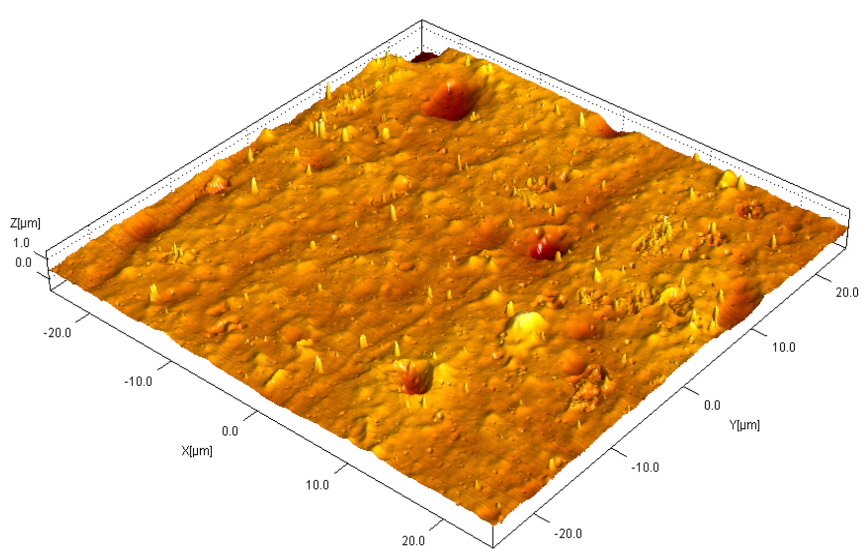

(b)

Figure 8 


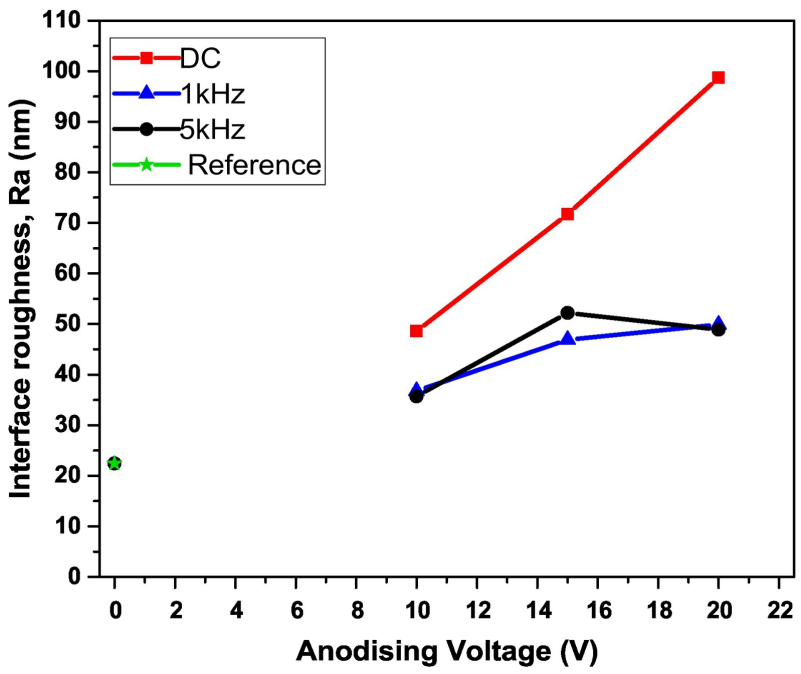

Figure 9 


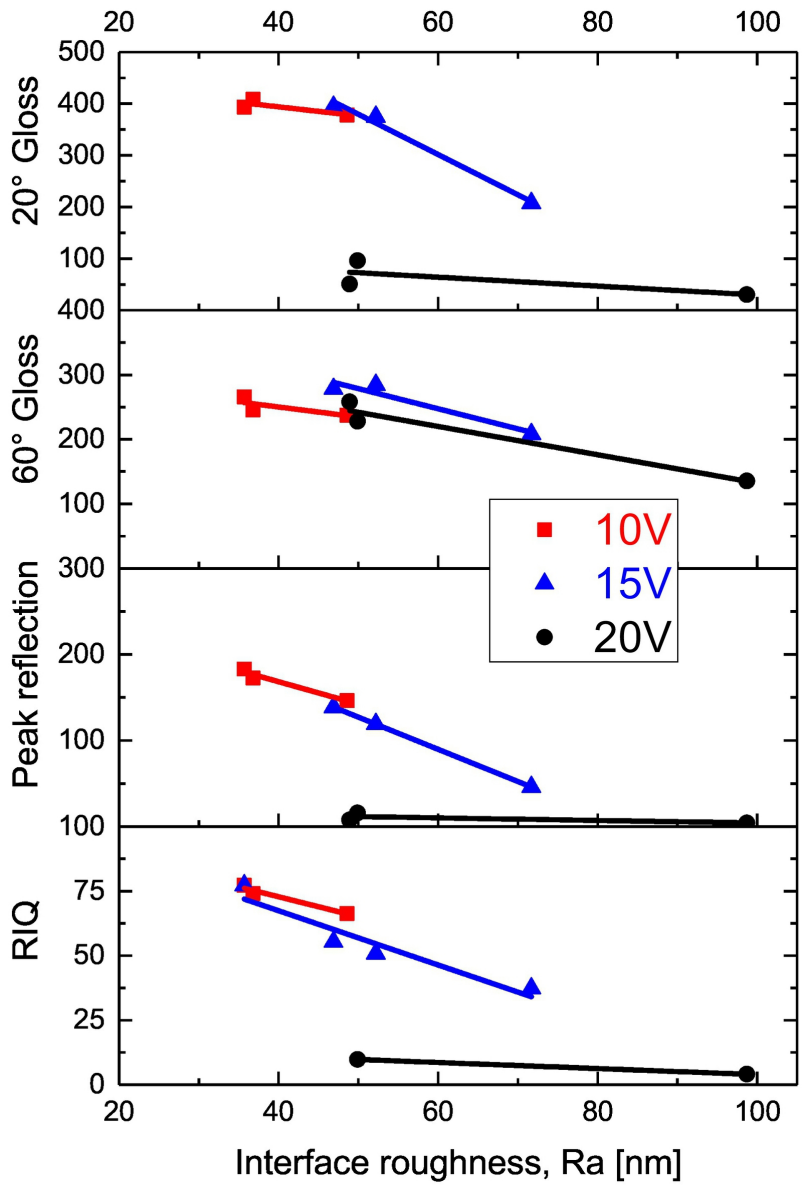

Figure 10 